\title{
Comparison between ozone monitoring data and modelling data, in Italy, from the perspective of health indicator assessments
}

\author{
A. De Marco, A. Screpanti, S. Racalbuto, T. Pignatelli, G. Vialetto, \\ F. Monforti \& G. Zanini \\ Italian Agency for New Technology, Energy and the Environment \\ (ENEA), Italy
}

\begin{abstract}
The need for comparison between monitoring data and modelling data on ozone comes both from the qualitatively and quantitatively scarce outcome of the Italian ozone monitoring network and, at the same time, from the necessity for assessment and validation of the modelling methodology. Indeed, the distribution of the monitoring stations in Italy is not uniform and a dramatic lack of data is observed in all of the southern Italian areas. A number of different strategies can be applied to obtain a uniform distribution of data within the territory. The methodology of "spatialization" is described in the paper and applied to the health exposure indicator SOMO35 (developed by the WHO), pursuing the ultimate objective of identifying risk areas for the population. Such areas are then compared with similar areas from the analysis carried out by the Italian Integrated Assessment model RAINS Italy. The comparative analysis reported in this paper highlighted the differences, deepening the background rationale and ultimately increasing the robustness of the health risk analysis. Moreover, maps generated by the model could also be used to identify critical areas not covered by monitoring stations, so driving a more cost efficient allocation of expensive equipment.
\end{abstract}

Keywords: SOMO35, kriging, RAINS Italy, health risk area, tropospheric ozone. 


\section{Introduction}

There is a more and more increasing interest in the analyses of the health effects caused by exposure of the population to ground level ozone. Scientific studies have demonstrated that exposure to ozone concentrations in the air has several significant adverse effects on human health, causing breathing problems, triggering asthma, reducing lung function and causing lung diseases (WHO [1]). In particular, the recent WHO update of the air quality guidelines to protect public health has concluded that these effects could occur at every ground level ozone concentration, and a possible threshold, if any, might be close to background levels and not determinable (TFH [2]).

A number of different strategies can be used to obtain a uniform distribution of ozone data, both measured and calculated, within the territory, to be used in the calculation of the health exposure indicator, pursuing the ultimate objective of identifying risk areas for the population. In this paper a health effect indicator, based upon a proper cumulated exposure indicator, the SOMO35, was selected for use following the suggestion given by the Joint UN/ECE-WHO Task Force on Health (TFH [2]). A possible approach to reaching the objective could be the "spatialization", the SOMO35 calculated from data measured through the ozonemonitoring network. Generally speaking, this approach requires a huge and uniform network of monitoring stations, which are very expensive to implement and indeed not necessary in those parts of the territory with a quite low density of population, where ozone does not represent a problem. Referring to the Italian context, the qualitatively and quantitatively scarce outcome of the Italian ozonemonitoring network makes this approach insufficient to achieve the objective. A different approach, complementary to the monitoring network, is the development of suitable models to reproduce the ozone concentration fields, with a sufficient degree of accuracy. The RAINS (Regional Air pollution INformation and Simulation) model, in its Italian version (RAINS-Italy), is an Integrated Assessment Model developed within joint research project ENEA-IIASA, (International Institute for Applied Systems Analysis), used along with a Eulerian Model for the dispersion of the pollutants and the chemistry of the atmosphere, is a suitable tool for estimating the ground level ozone concentration and its effects on human health. In this paper, the calculated values of SOMO35 are compared with the ozone-monitored value properly converted in SOMO35. Also, a preliminary assessment of the health impact from ozone, in terms of premature deaths, is shown.

\section{Integrated Assessment Modelling System MINNI}

The MINNI Modelling System is the result of a project led by ENEA and developed on behalf of the Italian Ministry for the Environment, Land and Sea, aimed at providing the policy with scientific support in the elaboration and assessment of air pollution policies, at international and national levels, by means of the more recent understanding of the atmospheric processes peculiarly characterizing the Italian territory. The two key components of MINNI (a full 
description can be found in Zanini et al, [3]), are the Atmospheric Modelling System (AMS-Italy), a multi-pollutant Eulerian model for dispersion of the pollutants and the chemistry of the atmosphere, and the integrated assessment model RAINS-Italy, developed in collaboration with IIASA, owner of the original RAINS_Europe model (fig. 1). AMS-Italy simulates the air pollution dynamics and the multiphase chemical transformations of the pollutants, providing concentrations and depositions on a hourly and yearly basis of $\mathrm{SO}_{2}$, $\mathrm{NO}_{\mathrm{x}}, \mathrm{NH}_{3}, \mathrm{PM}_{10}, \mathrm{PM}_{2.5}$ and $\mathrm{O}_{3}$, with spatial resolutions from $20 \mathrm{~km} \times 20 \mathrm{~km}$ to $4 \mathrm{~km} \times 4 \mathrm{~km}$. RAINS-Italy calculates emission scenarios for $\mathrm{SO}_{2}, \mathrm{NO}_{\mathrm{x}}, \mathrm{NH}_{3}$, $\mathrm{PM}_{10}, \mathrm{PM}_{2.5}$ and VOCs, as well as estimations of the costs associated with the implementation of the abatement technologies, and impact assessment on the environment and the human health. The RAINS-Italy model has a spatial resolution of $20 \mathrm{~km} \times 20 \mathrm{~km}$. The two components complement each other. AMS-Italy feeds RAINS-Italy with fine resolution Atmospheric Transfer Matrices (ATMs, source-receptor relationship coefficients) allowing RAINS-Italy to estimate average annual PM concentrations, $\mathrm{SO}_{2}$ and $\mathrm{NO}_{\mathrm{x}}$ depositions, for the purposes of acidification and eutrophication and health impact, in terms of Life Expectancy Reduction $\left(\mathrm{PM}_{2.5}\right)$ and Premature Deaths (ozone).

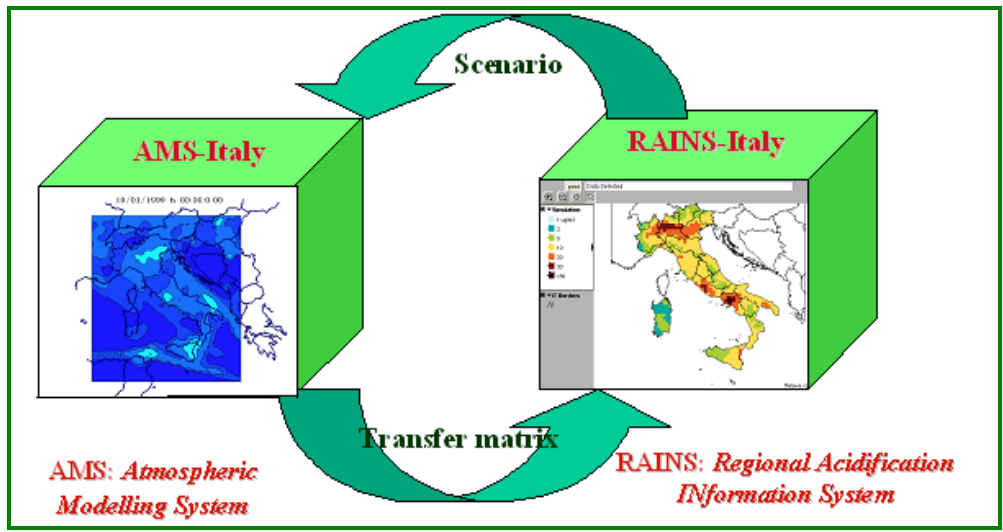

Figure 1: Block scheme of the MINNI modelling system.

The core of the AMS-Italy is in the three-dimensional Eulerian chemical-transport model FARM (ARIANET [4]), which is derived from STEM (Carmichael et al. [5]). The code has been developed so that different chemical scheme can be implemented; within MINNI, the SPARC90 gas-phase scheme has been employed. As for PM, two approaches are available: the AERO0 simplified PM 'bulk' module, as implemented in the EMEP Eulerian unified model (EMEP [6]), considering the ammonia-nitric, acid-sulphuric, acid-water system, and the AERO3 Models-3/CMAQ module (Binkowski [7]), following the modal approach and also including secondary organic particulate. Atmospheric transfer matrices for RAINS-Italy have been calculated using the 
first approach, while the second one has been employed for specific studies. The reference meteorological year for AMS-Italy calculations is 1999.

RAINS-Italy has been used for the purposes of this paper to create maps of SOMO35 through the ATMs. RAINS-Italy (Vialetto et al. [8]) maintains the same features of the RAINS-Europe model (Amann et al. [9], IIASA web site [10]). The latest emission scenarios (D'Elia et al. [11]) elaborated with the EU NEC Directive review, have been used in this study.

\section{Assessment of ozone concentrations by MINNI}

The MINNI modelling system is suitable for reproducing the ozone concentration fields with a reasonable degree of accuracy. In figure 2 , the comparison between the data monitored through the EMEP monitoring network stations and the data calculated with the AMS-Italy at the same locations for the year 1999 is shown. The results show a good agreement during the summer season, although the agreement seems to decrease along the rest of the year, where the model seems to overestimate the ozone concentrations. However, this result is not very surprising, for a number of reasons; the most important is that the model has been tailored in order to have the best performance at the higher temperatures, e.g. during the summer months, when the most adverse effects on human health and the environment are assumed. Indeed, the overestimation of the ozone concentrations, at lower temperatures, seems to be a general characteristic of the atmospheric dispersion models, as suggested from the analysis of the result of the recent City-Delta programme (Amman et al. [12]), although this fact has no serious consequences, due to the scarce effects of the ozone on the environment and health during the winter time. The results shown in fig. 2 also ensure that the ozone maps calculated by RAINS-Italy have a similar degree of accuracy, in reproducing ozone distribution, at the reference meteorological year 1999 .

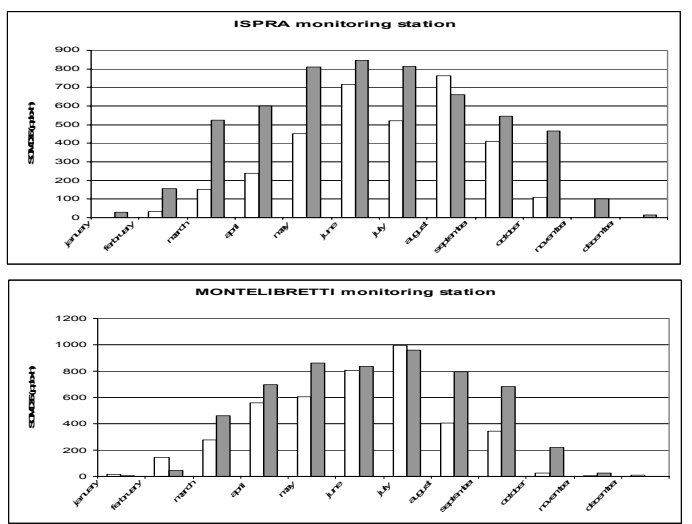

Figure 2: Comparison between the data monitored through the EMEP monitoring network stations and the data calculated with the AMSItaly, at the same locations, for the year 1999. 


\section{The Italian ozone monitoring station network}

The Italian monitoring data come from regional and local databases (Regional Authority and Local Environment Protection Agencies, ARPA), based upon Air Quality monitoring stations and located both in urban and rural areas, although they are not uniformly distributed. In this paper, only rural or sub-urban stations are taken into account, because in the urban stations, measurements of tropospheric ozone are influenced by the presence of other pollutants, such as $\mathrm{NO}_{\mathrm{x}}$. Moreover, only those stations having at least $75 \%$ of yearly availability have been selected. Original data are recorded hourly. The monitoring network stations used in this work are shown in figure 3. SOMO35 is then calculated for the whole year, according to the following methodology:

- $\quad$ floating 8 hour mean value calculation;

- $\quad$ identification of the highest 8 hour mean value, over 24 hours;

- sum of the exceedances over $35 \mathrm{ppb} / \mathrm{h}$, within the identified highest mean value.

Meteorological data come from UCEA (Central Office of Agrarian Ecology) database, which provides on-line monitoring data collected from stations, uniformly distributed over the national territory. In particular, average daily temperatures and average daytime humidity values have been used in the correlation for the ozone calculation (Hartkamp et al. [13]).

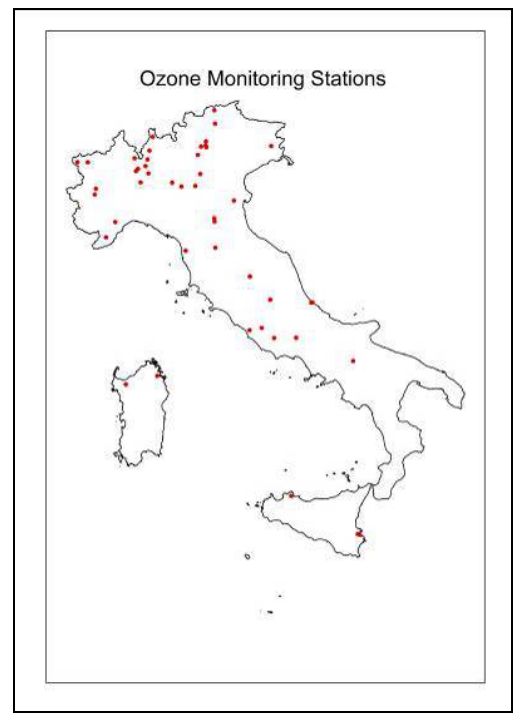

Figure 3: The monitoring network stations used for the calculation of the ozone concentrations.

With regard to the altitude, the Digital Elevation Model (DEM) used in this paper has a grid resolution of $500 \mathrm{~m} \times 500 \mathrm{~m}$. As is well known in literature, a relevant correlation exists between altitude and ozone concentrations 
(Bronnimann et al. [14]), resulting in higher ozone concentrations in the mountain areas.

\section{The spatialization methodology}

With regard to the spatialization methodology, in this paper two spatialization methodologies have been used, as described below.

Kriging interpolation. Kriging is a geo-statistical interpolation technique considering both the distance and the degree of variation between known data points, in estimating values in areas with no monitoring stations. A kriging estimate is a weighted linear combination of the known sample values around the point to be analysed. Applied properly, kriging allows deriving weights, which result in optimal and unbiased estimates. The construction of the semi-variogram of the data, used as weights nearby sample points during the interpolating, is also allowed by the kriging routine. The kriging routine also provides the users with a tool to evaluate the data trends. In the kriging methodology a proper variable called the semivariance is used to express the degree of relationship between points on a surface. The semivariance is simply defined as a half of the variance of the differences between all possible points spaced a constant distant apart. The semivariance at a distance $\mathrm{d}=0$ is 0 , because there are no differences between points that are compared to themselves. However, as a point is compared with other points at increasing distances, the semivariance increases. At some distance, the semivariance will become approximately equal to the variance of the whole surface itself. This is the maximum distance at which a point value on the surface is related to another point value. The calculation of semivariance between sample pairs at different distance combinations has been analyzed. The initial distance used is called Lag distance, which is increased by constant steps through the range. In the semivariogram graph, the variance between points is reported versus the distance at which the variance is calculated. The technique used in this paper is an ordinary kriging. This method assumes that the data set has a fixed variance but also a non-fixed mean value within the searching circle area. This method is highly reliable and is recommended for most of the data sets.

Cokriging interpolation. Cokriging has been traditionally used to minimize the variance of the error by taking into account the spatial correlation between the variables of interest and the secondary variables. The Cokriging is a moderately fast interpolator that can be exact or smoothed depending on the measurement error model. Cokriging uses multiple datasets and is very flexible, allowing investigating graphs of cross-correlation and auto-correlation. The flexibility of Cokriging requires a decision-process. Cokriging assumes the data are from a stationary stochastic process, while some methods assume normal-distributed data. In this paper, the daily mean temperature and the daily relative humidity (data derived from UCEA) have been used as a co-variable for the DEM. 


\section{Comparison between monitoring and calculated data}

In figure 4 the maps of SOMO35 are shown, referred to the year 2000, obtained from the data measured in the Italian monitoring network stations (right side) by ordinary kriging and the data calculated with the RAINS-Italy model (left side). The map obtained with the RAINS-Italy model was processed by kriging to allow the comparison with the interpolation obtained by monitoring data.

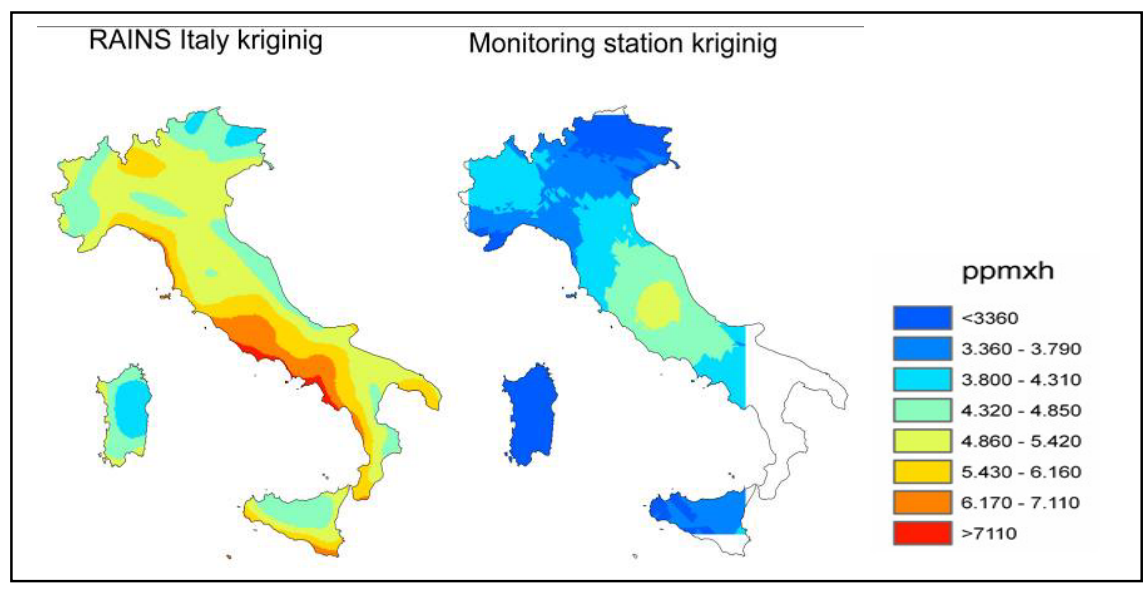

Figure 4: $\quad$ SOMO35 for the year 2000 in Italy calculated from the data measured in the monitoring network stations (right side) and with the RAINS-Italy model (left side).

By the comparison of the two different approaches it appears clear that the values are generally higher in the RAINS derived map in respect of the measured interpolated data. Moreover, there are some differences especially for the southern coastal zone in the RAINS map and for the central spot in the measured map. The differences are probably due to the starting data. In fact, the RAINS model, as previously described, is based on a pollutants atmospheric dispersion model, that covers all of the national territory and also the Mediterranean Sea, while in monitoring mapping the results take into account the distribution of the measurements stations that are obviously not present in the sea. The hot spot in the middle of Italy is related to high values of ozone recorded in the rural and mountain station of Leonessa.

As for other factors increasing the differences between the two maps, one is that the map calculated with the RAINS-Italy model refers to the meteorological year 1999, while the monitoring data obviously reflect the true meteorological condition of the year 2000. Moreover, the ozone directive, adopted by the Italian legislative decree, establishes a sampling efficiency threshold of $75 \%$ of available data to consider the dataset validated. This implies a possible underestimation of the real health effect for the measured maps. 
All of these limitations are also found in the Cokriging interpolation of measured data (data not shown). The differences between the values estimated by the RAINS model and the interpolated measured data expressed as a percentage is reported in table 1 for all the different kinds of interpolation tested. As shown in the table, the use of a more complex interpolation technique is not expressed in a drastic improvement of the results. It has to be noted that the reduced sampling efficiency of the monitoring stations used could justify a lot of the discrepancies observed in the values.

Finally, using the RAINS-Italy model alone, preliminary maps of premature deaths due to ozone have been developed, and they are shown in figure 5.

Table 1: $\quad$ Mean percentage of distance between modelled and interpolated measured data.

\begin{tabular}{|l|c|}
\hline & $\%$ \\
\hline Kriging & 29,23 \\
\hline Cokriging DEM & 27,45 \\
\hline Cokriging meteo DEM & 28,5 \\
\hline
\end{tabular}

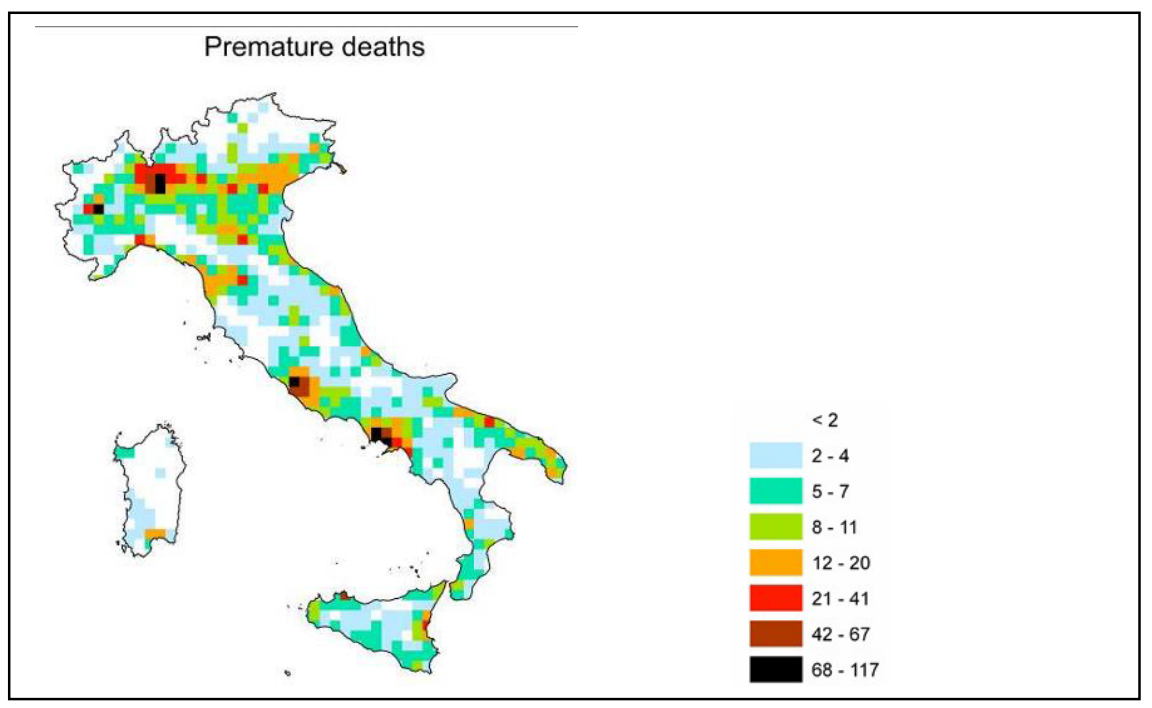

Figure 5: Preliminary map of premature deaths due to ozone concentrations, as calculated with the RAINS-Italy model (year 2000). 


\section{Conclusion}

Considering the constraints and the differences in the two approaches, as discussed above, which result in indirectly comparable maps, some considerations can be drawn. In the North of Italy and in some regions in Central Italy, there is evidence of a strong potential health impact, which may result in considerable premature deaths. Due to the method of calculation applied, the measured map seems to underestimate the cumulative exposure to ozone and therefore the health impact. The lack of monitored data in a large part of the Italian territory, particularly in all the southern Italian areas, makes the modelling outcome the unique source of data in these areas. In light of the above discussion, the health impact analysis, carried out by the RAINS-Italy model, seems reasonably more reliable. From this point of view, the comparison has also highlighted the need for a significant improvement in the monitoring network, given the essential role played by the quality of the monitoring data in the model assessment and validation.

\section{References}

[1] WHO (2006). Use of the air quality guidelines in protecting public health: a global update. Fact sheet WHO/313, October 2006.

[2] TFH (2003). Modelling and assessment of the health impact of the particulate matter and ozone. EB.AIR/WG1/2003/11. United Nations Economic Commission for Europe, Task Force on Health, Geneve

[3] Zanini G., Pignatelli T., Monforti F., Vialetto G., Vitali L., Brusasca G., Calori G., Finardi S., Radice P., Silibello C. (2005); The MINNI Project: An Integrated Assessment Modelling System for policy making. In Zerger, A. and Argent, R.M. (eds) MODSIM 2005 International Congress on Modelling and Simulation. Modelling and Simulation Society of Australia and New Zealand, pp. 2005-2011. ISBN: 0-9758400-2-9. December 2005, http://www.mssanz.org.au/modsim05/papers/zanini.pdf

[4] ARIANET (2004) FARM (Flexible Air quality Regional Model) Model formulation and user manual. Arianet report R2004.04, Milano.

[5] Carmichael G.R., Uno I., Padnis M.J., Zhang Y. and Sunwoo Y., (1998) Tropospheric ozone production and transport in the springtime in east Asia. J. Geophys. Res., 103, 10649-10671.

[6] EMEP, (2003) Transboundary acidification, eutrophication and ground level ozone in Europe. Part I: Unified EMEP model description. EMEP status Report 1/2003.

[7] Binkowski F. S., (1999). The aerosol portion of Models-3 CMAQ. In Science Algorithms of the EPA Models-3 Community Multiscale Air Quality (CMAQ) Modeling System. Part II: Chapters 9-18. D.W. Byun, and J.K.S. Ching (Eds.). EPA-600/R-99/030, National Exposure Research Laboratory, U.S. Environmental Protection Agency, Research Triangle Park, NC, 10-1-10-16. 
[8] Vialetto, G., Contaldi, M., De Lauretis, R., Lelli, M., Mazzotta, V., Pignatelli, T. (2005); Emission Scenarios of Air Pollutants in Italy using Integrated Assessment Models. Pollution Atmosphérique, n.185, p.71, 2005.

[9] Amann, M., Cofala, J., Heyes, C., Klimont, Z. \& Shopp, W. (1999). The RAINS model: a tool for assessing regional emission control strategies in Europe, Pollution Atmospherique, Numero speciale, December 1999.

[10] IIASA, www.iiasa.ac.at/ rains/index.html

[11] D’Elia, I., Contaldi, M.,, De Lauretis, R., Pignatelli, T., Vialetto, G. (2007); Emission Scenarios of Air Pollutants in Italy (In Italian). Submitted to Ingegneria Ambientale, 2007

[12] Amann, M., Cofala, J., Heyes, C., Klimont, Z. Mechler, R., Posch, M., Shopp, W. (2004). The Regional Air Pollution Information and Simulation (RAINS) model: Review 2004. IIASA Interim Reports, February 2004.

[13] Hartkamp AD, De Beurs K, Stein A, White JW: Interpolation Techniques for Climate Variable. NRG-GIS Series 99-01. Mexico, D.F.:CIMMYT, 1999

[14] Bronnimann S, Luterbacher J, Schmutz C, Wanner H): Variability of total ozone at Arosa, Switzerland, since 1931 related to atmospheric circulation indices. Geophys. Res. Let., 27:2213-2216, 2000 